Marquette University

e-Publications@Marquette

Chemistry Faculty Research and Publications

Chemistry, Department of

$1-1-2018$

\title{
Human P450 CYP17A1: Control of Substrate Preference by Asparagine 202
}

Michael C. Gregory

University of Illinois at Urbana-Champaign

Piotr J. Mak

Marquette University, piotr.mak@marquette.edu

Yogan Khatri

University of Illinois at Urbana-Champaign

James R. Kincaid

Marquette University, james.kincaid@marquette.edu

Stephen G. Sligar

University of Illinois at Urbana-Champaign

Accepted version. Biochemistry, Vol. 57, No. 5 (2018): 764-771. DOI. (C) 2017 American Chemical Society. Used with permission. 
Marquette University

e-Publications@Marquette

\section{Chemistry Faculty Research and Publications/College of Arts and Sciences}

This paper is NOT THE PUBLISHED VERSION; but the author's final, peer-reviewed manuscript. The published version may be accessed by following the link in th citation below.

Biochemistry, Vol. 57, No. 5 (December 28, 2017): 764-771. DOI. This article is (C) American Chemical Society and permission has been granted for this version to appear in e-Publications@Marquette. American Chemical Society does not grant permission for this article to be further copied/distributed or hosted elsewhere without the express permission from American Chemical Society.

\section{Human P450 CYP17A1: Control of Substrate Preference by Asparagine 202}

Michael G. Gregory

Department of Biochemistry, University of Illinois at Urbana-Champaign, 505 South Goodwin Avenue, Urbana, IL Piotr J. Mak

Department of Chemistry, Marquette University, Milwaukee, WI

Yogan Khatri

Department of Biochemistry, University of Illinois at Urbana-Champaign, 505 South Goodwin Avenue, Urbana, IL James R. Kincaid

Department of Chemistry, Marquette University, Milwaukee, WI

Stephen G. Sligar

Department of Biochemistry, University of Illinois at Urbana-Champaign, 505 South Goodwin Avenue, Urbana, IL Department of Chemistry, University of Illinois, Urbana, IL

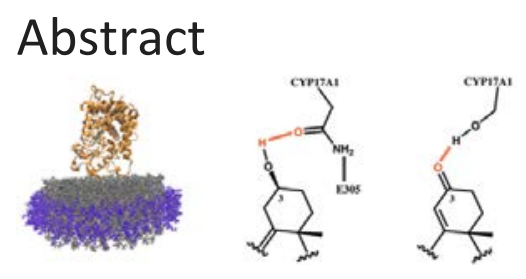


CYP17A1 is a key steroidogenic enzyme known to conduct several distinct chemical transformations on multiple substrates. In its hydroxylase activity, this enzyme adds a hydroxyl group at the $17 \alpha$ position of both pregnenolone and progesterone at approximately equal rates. However, the subsequent 17,20 carbon-carbon scission reaction displays variable substrate specificity in the numerous CYP17A1 isozymes operating in vertebrates, manifesting as different $K_{\mathrm{d}}$ and $k_{\text {cat }}$ values when presented with $17 \alpha$-hydroxypregnenlone (OHPREG) versus $17 \alpha$-hydroxyprogesterone (OHPROG). Here we show that the identity of the residue at position 202 in human CYP17A1, thought to form a hydrogen bond with the A-ring alcohol substituent on the pregnenenucleus, is a key driver of this enzyme's native preference for OHPREG. Replacement of asparagine 202 with serine completely reverses the preference of CYP17A1, more than doubling the rate of turnover of the OHPROG to androstenedione reaction and substantially decreasing the rate of formation of dehydroepiandrosterone from OHPREG. In a series of resonance Raman experiments, it was observed that, in contrast with the case for the wild-type protein, in the mutant the $17 \alpha$ alcohol of OHPROG tends to form a H-bond with the proximal rather than terminal oxygen of the oxy-ferrous complex. When OHPREG was a substrate, the mutant enzyme was found to have a $\mathrm{H}$-bonding interaction with the proximal oxygen that is substantially weaker than that of the wild type. These results demonstrate that a single-point mutation in the active site pocket of CYP17A1, even when far from the heme, has profound effects on steroidogenic selectivity in androgen biosynthesis.

P450 CYP17A1 (CYP17A1) is a steroidogenic enzyme of critical importance in the pathway leading to the formation of androgens (Figure 1). Primarily localized in tissues of the adrenal gland and sex organs, the multifunctional CYP17A1 catalyzes the $17 \alpha$ hydroxylation of pregnenolone and progesterone as well as the subsequent 17,20 carbon-carbon bond scission or " $\mathrm{C}-\mathrm{C}$ lyase" that gives rise to dehydroepiandrosterone (DHEA) and androstenedione $(A D) .(1,2)$ Though subsequent biological transformations are required to generate the potent androgen receptor agonists testosterone and dihydrotestosterone, the upstream lyase activity of CYP17A1 is the first committed step in their production. The importance of these androgens in the proliferation of prostate cancer, coupled with the disappointing performance of $5 \alpha$-reductase inhibitors, has created intense interest in this enzyme, most notably resulting in the development and approval of the inhibitor, abiraterone acetate. A groundbreaking 2012 publication described the crystal structure of CYP17A1,(3) yet much regarding the nature of key substrate-protein interactions that drive the selectivity of CYP17A1 remains unknown.
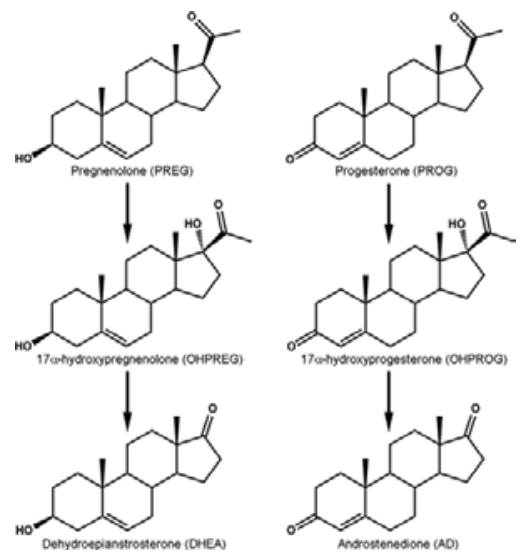

Figure 1. Structures of substrates and products of CYP17A1.

Human CYP17A1 is known to exhibit a strong preference for hydroxypregnenolone (OHPREG) over hydroxyprogesterone (OHPROG) when catalyzing carbon-carbon scission chemistry, despite its ability to hydroxylate pregnenolone and progesterone at roughly equivalent rates. $(4,5)$ This roughly 50 -fold difference in terms of $k_{\text {cat }} / K_{\mathrm{m}}$ favoring OHPREG drives steroidogenic flux in humans predominantly through the OHPREG to DHEA pathway. However, preference for the OHPREG substrate is not conserved across CYP17 isozymes operating in the vertebrata subphylum. Whereas some isozymes have the same substrate preference as human 
CYP17A1, others have no substrate preference and still others more favorably catalyze the OHPROG to AD reaction. $(6,7)$ Although detailed studies of the activity of CYP17 enzymes across a range of species are still a work in progress, the Usanov laboratory has carefully evaluated the activities of various vertebrate CYP17 enzymes under identical conditions and classified their activities as favoring OHPREG or OHPROG or as having no preference(6) (Table 1). Insight into the origin of these discrete substrate preferences was finally provided in seminal work by the Scott laboratory in which the crystal structure of truncated human CYP17A1 was determined first in the presence of its inhibitor, abiraterone, as well as subsequent structures of the $\mathrm{A} 105 \mathrm{~L}$ CYP17A1 mutant in the presence of all four native substrates. $(3,8)$ In all cases, the pregnene- nucleus is perpendicular to the heme with its D-ring juxtaposed against the iron atom and the $\beta$-face of the steroid directed toward the I-helix. Importantly, the $\mathrm{C}-3$ substituent $(-\mathrm{OH}$ or $=\mathrm{O})$ is generally positioned within hydrogen bonding distance of asparagine 202 , which projects its side chain from the F-helix into the active site cavity.

Table 1. Sequence Alignment of Various CYP17 Enzymes with Associated Turnover Numbers with OHPREG or OHPROG as a Substratea

\begin{tabular}{|c|c|c|c|}
\hline species & sequence & OHPREG & OHPROG \\
\hline Homo sapiens & LNVIQNY-N-EGIIDNL & 1.4 & NMb \\
\hline Bos taurus & LKAIQNV-N-DGILEV & 4.6 & NMb \\
\hline Bos bison & LKAIQNV-N-DGILEV & 1.7 & NM $\underline{b}$ \\
\hline Felis catus & LKIIQNY-N-EGILKTL & 0.3 & NM므 \\
\hline Cavia porcellus & LVTIRRF-T-TGFVNS & NM므 & 1.7 \\
\hline Equus caballus & LETMQNY-H-KGILE & 10.5 & 27.1 \\
\hline Rattus norvegicus & LTAIKTF-T-EGIVDA & 0.8 & 2.2 \\
\hline Xenopus laevis & FEEMLAY-S-KGIVDT & 0.09 & 0.14 \\
\hline
\end{tabular}

aproduct formation is expressed in units of nanomoles per minute per nanomole of P450 as documented by Usanov et al.(6) ${ }^{\mathrm{b}}$ Not measured.

Emerging evidence suggests that even small changes in the hydrogen bonding patterns at position 202, which is remote from the heme active center, can substantially impact the position of substrates near the active ironoxygen intermediate responsible for catalysis in a manner that may either facilitate or hinder product formation.(9) The choice between a keto or alcohol group at the $\mathrm{C}-3$ position directs the $17 \alpha-\mathrm{OH}$ group of the substrate to form a hydrogen bond (H-bond) to either the proximal (OHPREG) or distal (OHPROG) oxygen of the oxy complex that persists following the subsequent one-electron reduction that forms the peroxo-ferric intermediate.(10) This is an essential distinction owing to the mechanism employed by CYP17A1 in the formation of androgens. Among the steroidogenic P450s, CYP17A1 is believed to be unique in that the $\mathrm{C}-\mathrm{C}$ lyase chemistry can be initiated not by the traditional ferryl-oxene species but by a nucleophilic attack on the C-20 carbonyl by a reactive peroxo-ferric intermediate. $(5,10-13)$ The resultant peroxo hemiketal may then decompose to the androgen product and acetic acid. Importantly, this mechanism is dependent upon unencumbered access to $\mathrm{C}-20$ by the distal oxygen of the peroxoanion.

To determine the relevance of N202 in substrate specificity, sequence alignments were performed (Table 1), and the residue identity at position 202 was compared to substrate preference, in terms of the product formation rates of the various vertebrate CYP17 enzymes published previously by the Usanov group.(6) In the case of enzymes that favor OHPREG as a substrate, an asparagine residue is generally conserved. However, in enzymes with an alternate preference, a serine or threonine residue generally occupies this position. On the basis of side chain torsion or mobility in proteins containing N202, this residue can potentially donate a H-bond to the keto group of OHPROG or accept a H-bond from the alcohol C-3 substituent on OHPREG substrates, respectively 
(Figure 2A,B).(8) We hypothesize that the alcohol presented by serine and threonine residues would form a favorable interaction with the keto fragment presented by OHPROG (Figure 2D). Expanding on results from the Usanov group in which this subtle alteration in side chain identity substantially impacted product formation rates, we postulated that this alcohol would fail to form the H-bonding interaction with OHPREG or the requisite geometry to form such an interaction would orient the substrate unfavorably for catalysis (Figure 2C).

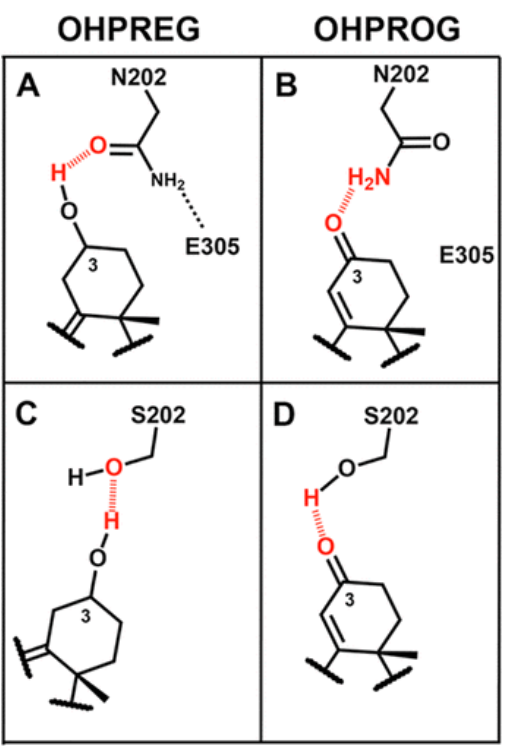

Figure 2. Schematic of hydrogen bonding interactions between substrates and asparagine or serine 202.

To explore the role of the residue at position 202, which is located far from the heme center, we generated the N202S mutant in human CYP17A1 with the thought that this would reverse the substrate specificity of this isozyme. We reasoned that the choice of serine versus threonine or histidine was least likely to result in a steric clash owing to the diminished side chain bulk relative to other residues observed in other CYP17 isozymes. We further hypothesized that such a mutation would alter the position of the substrate in the active site. Among other alterations in individual catalytic steps, loss of the $\mathrm{H}$-bond accepting character of the asparagine residue that directs the $17 \alpha$ alcohol to hydrogen bond with the proximal oxygen in the oxy-and peroxo-ferric forms could now explicitly favor OHPROG as a substrate in the $\mathrm{C}-\mathrm{C}$ lyase reaction. The resultant mutant of CYP17A1 was expressed in high yield and purified to electrophoretic homogeneity prior to incorporation into Nanodiscs. The Nanodisc system consists of CYP17A1 embedded in a 1-palmitoyl-2-oleoyl-sn-glycero-3-phosphocholine (POPC) lipid bilayer encircled by a solubilizing amphipathic scaffold protein.(14-17) Use of this system permits interrogation of the full-length and membrane-bound CYP17A1 protein under essentially native but controlled conditions and has found wide use in the study of this and many other proteins.(18)

\section{Experimental Procedures}

\section{Expression, Purification, and Nanodisc Incorporation of N202S CYP17A1}

The N202S mutant was generated using a codon-optimized full-length human wild-type CYP17A1 synthetic gene (DNA 2.0) in the pCWori plasmid. Mutagenesis was performed using iProof polymerase with primers obtained from Integrated DNA Technologies. Forward primers were 5'TGAATGTGATCCAGAATTACAGTGAGGGCATCATCGACAAT-3'. Reverse primers were $5^{\prime}$ ATTGTCGATGATGCCCTCACTGTAATTCTGGATCACATTCA-3'. Sequencing was performed by ACGT Inc. Expression, purification, and Nanodisc incorporation for both wild-type and N202S CYP17A1 were performed as previously described. $(9,19)$ 


\section{Substrate Binding Titrations}

Spectral dissociation constants were determined by the sequential addition of substrate dissolved in methanol to a cuvette containing $1.5 \mu \mathrm{M}$ CYP17A1 in $100 \mathrm{mM}$ potassium phosphate (pH 7.4) and $50 \mathrm{mM} \mathrm{NaCl}$. Electronic absorption spectra were recorded from 350 to $800 \mathrm{~nm}$ in a Cary 300 spectrophotometer at $25^{\circ} \mathrm{C}$. Spectral dissociation constants were estimated by plotting the change in the peak to trough $A_{390}-A_{420}$ difference spectra versus substrate concentration and fitting the resultant binding isotherm to the quadratic tight binding equation.(20) For each substrate/enzyme pair, titrations were performed in triplicate, and the percent high spin was calculated at each substrate concentration using a peak to trough extinction coefficient in the difference spectra $\left(\varepsilon_{390-420}\right)$ of $100 \mathrm{mM}^{-1} \mathrm{~cm}^{-1}$. $(21)$ The error is reported as \pm 1 standard deviation.

\section{Product Formation}

Rat cytochrome P450 oxidoreductase and cytochrome $b_{5}$ were expressed and purified as described previously. $(22,23)$ These proteins were inserted into Nanodiscs containing wild-type or N202S CYP17A1 as described by Grinkova et al.(24) Product formation rates were determined under saturating concentrations (40 $\mu \mathrm{M}$ ) of OHPREG or OHPROG in $100 \mathrm{mM}$ potassium phosphate buffer $(\mathrm{pH} \mathrm{7.4)}$ and $50 \mathrm{mM} \mathrm{NaCl}$. Mixtures containing $0.2 \mathrm{nmol}$ of wild-type or N202S CYP17A1 Nanodiscs, $0.8 \mathrm{nmol}$ of cytochrome $b_{5}$, and $0.8 \mathrm{nmol}$ of cytochrome $\mathrm{P} 450$ oxidoreductase in $1.0 \mathrm{~mL}$ of buffer were warmed to $37^{\circ} \mathrm{C}$, and the reaction was initiated by addition of $400 \mathrm{nmol}$ of NADPH. After $10 \mathrm{~min}$, reactions were quenched by addition of $50 \mu \mathrm{L}$ of $8.9 \mathrm{~N} \mathrm{H}_{2} \mathrm{SO}_{4}$, and mixtures were flash-frozen in liquid $\mathrm{N}_{2}$ and stored at $-80^{\circ} \mathrm{C}$.

Methods for extraction and quantitation of the products have been described in detail elsewhere. $(5,13$, 25) Briefly, products were extracted with $1.5 \mathrm{~mL}$ of dichloromethane after addition of a progesterone internal standard and dried under a stream of $\mathrm{N}_{2}$. Products of the OHPROG to AD reaction were analyzed by reversedphase high-performance liquid chromatography after reconstitution in $100 \mu \mathrm{L}$ of methanol. Separation was achieved using an ACE3 $\mathrm{C}_{18}$ column and a linear gradient beginning with a 5:5:90 methanol:acetonitrile:water ratio and ending with a 45:45:10 methanol:acetonitrile:water ratio. Mobile phases were supplemented with $0.2 \%$ formic acid, and the product was observed optically at $240 \mathrm{~nm}$. The DHEA product was analyzed on a FIDequipped gas chromatograph fitted with a 30 m DB-17 capillary column as described previously.(13)

\section{Sample Preparation for Resonance Raman ( $r R$ ) Spectroscopy}

Ferric rR samples contained $150 \mu \mathrm{M}$ N202S CYP17A1 Nanodiscs in $100 \mathrm{mM}$ potassium phosphate buffer (pH 7.4) with $15 \%(v / v)$ glycerol and $450 \mu \mathrm{M}$ OHPREG or OHPROG. Oxy-ferrous samples contained $150 \mu \mathrm{M}$ N202S CYP17A1 Nanodiscs in $100 \mathrm{mM}$ potassium phosphate (pH 7.4), $250 \mathrm{mM} \mathrm{NaCl}$, and $30 \%$ (v/v) distilled glycerol. OHPREG, OHPROG, PREG, or PROG was added to a final concentration of $450 \mu \mathrm{M}$. Samples were deoxygenated under argon and reduced with a 1.5-fold molar excess of sodium dithionite in the presence of $3.8 \mu \mathrm{M}$ methyl viologen. Each sample was then chilled to $-15^{\circ} \mathrm{C}$ in a dry ice/ethanol bath and oxygenated by being bubbled with ${ }^{16} \mathrm{O}_{2}$ or ${ }^{18} \mathrm{O}_{2}$ for $5 \mathrm{~s}$. Samples were immediately flash-frozen in liquid $\mathrm{N}_{2}$ and stored at $77 \mathrm{~K}$.

\section{rR Sample Measurements}

Resonance Raman spectra of the oxy complexes were recorded using a Spex 1269 spectrometer attached to a Spec-10 liquid nitrogen-cooled detector with a 2048-pixel resolution (Princeton Instruments, Princeton, NJ). The emission line at $413.1 \mathrm{~nm}$ from a $\mathrm{Kr}^{+}$laser was focused by a cylindrical lens on the sample that was immersed in liquid nitrogen during data collection. The $\mathrm{rR}$ data were measured using this $413.1 \mathrm{~nm}$ line from the $\mathrm{Kr}^{+}$laser (Coherent Innova Sabre Ion Laser) and collected using back scattering $\left(180^{\circ}\right)$ geometry with the laser beam being focused by a cylindrical lens to form a line image on the frozen sample contained in $5 \mathrm{~mm}$ outside diameter NMR tubes (WG-5 ECONOMY, Wilmad). The NMR tubes were positioned into a homemade doublewalled quartz low-temperature cell filled with liquid nitrogen. The sample tubes were spun to avoid local 
heating. The laser power was adjusted to $\leq 1 \mathrm{~mW}$. All measurements were performed at $77 \mathrm{~K}$, and the total collection time was $\sim 3 \mathrm{~h}$ in the high-frequency region and $\sim 4 \mathrm{~h}$ in the low-frequency region. The slit width was set at $150 \mu \mathrm{m}$, and a $1200 \mathrm{~g} / \mathrm{mm}$ grating was used. Spectra were calibrated with fenchone (Sigma-Aldrich, Milwaukee, WI) and processed with Grams/32 Al software (Galactic Industries, Salem, NH).

\section{Results and Discussion}

\section{Substrate Binding and Product Formation of N202S CYP17A1}

In a first set of experiments, we characterized the stability and substrate binding properties of N202S CYP17A1 using electronic absorption spectroscopy. Once incorporated into Nanodiscs, the mutant protein is exceptionally stable, showing nearly $100 \%$ P450 in the ferrous:CO form. Soret maxima were identical to those of the wild-type enzyme: $417 \mathrm{~nm}$ for the ferric substrate free form, $393 \mathrm{~nm}$ in the ferric substrate-bound state, and $408 \mathrm{~nm}$ when the protein is reduced to the ferrous state with sodium dithionite. Spectral dissociation constant $\left(K_{s}\right)$ values for wild-type and N202S CYP17A1 were obtained by sequential additions to samples of the four native substrates from methanolic stocks while the change in spin state was being monitored. In the case of the wild-type enzyme, $K_{\mathrm{s}}$ values for both PREG and PROG were roughly equivalent at $66 \pm 11$ and $41 \pm 2.5 \mathrm{nM}$, respectively. Values for OHPREG and OHPROG were higher for the lyase substrates, and notable differences in affinity were distinguishable for the 17-OH derivatives. For OHPREG, the $K_{\mathrm{s}}$ was measured to be $170 \pm 15 \mathrm{nM}$, and for OHPROG, it was $550 \pm 17 \mathrm{nM}$ (igure 3).
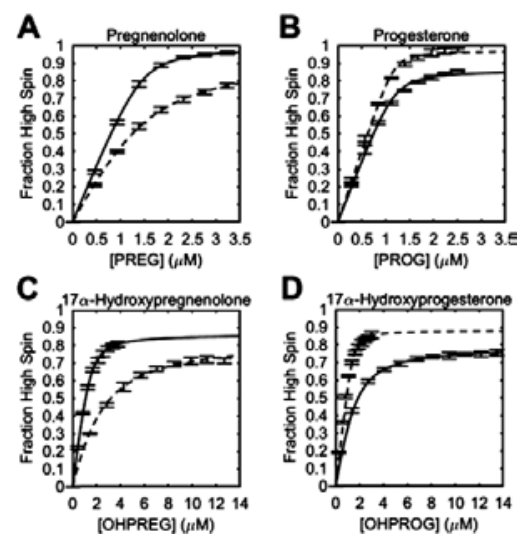

Figure 3. Substrate binding isotherms of wild-type and N202S CYP17A1. Solid lines denote data for the wild-type enzyme and dashed lines data for N202S.

When binding of hydroxylase substrates to the N202S enzyme was monitored, the results were significantly different from those observed for wild-type CYP17A1. Although PROG (Figure $3 B$ ) was largely unaffected by this mutation $\left(K_{\mathrm{s}}=16 \pm 4.1 \mathrm{nM}\right)$, binding of PREG was significantly impaired with a calculated $K_{\mathrm{s}}$ of $380 \pm 57 \mathrm{nM}$ (Figure $3 \mathrm{~A})$. Notably, the substrate preference of the lyase substrates was reversed for the mutant protein relative to that of the wild type. In the case of OHPREG, the $K_{\mathrm{s}}$ increased by nearly an order of magnitude to $1500 \pm 88 \mathrm{nM}$ (Figure $3 \mathrm{C}$ ). On the other hand, OHPROG bound substantially more tightly to N202S than to the wild type with a $K_{\mathrm{s}}$ of $53 \pm 12 \mathrm{nM}$ (Figure $3 \mathrm{D}$ ). These results support a key role for an interaction between the substrate $\mathrm{C}-3$ substituent and the residue present at position 202. Because the only other polar groups on the substrate (the $17 \alpha-\mathrm{OH}$ and C-20 carbonyl) are positioned near the heme and are not seen to form contacts with protein side chains in any available crystal structures,(8) specific favorable interactions between residue 202 and A-ring keto or alcohol groups are likely essential determinants in dictating binding affinity.

Another important probe of interaction of the ligand with the enzyme is the extent to which the P450 is converted to the "high-spin" state as substrate binding displaces water as the sixth ligand of the heme iron.(21) In the case of the wild-type enzyme, binding of PREG resulted in essentially complete low- to high-spin 
conversion, while PROG stimulated only a $90 \%$ transition to the high-spin form. In contrast, for this set of substrates, experiments with the N202S mutant exhibited behavior that was the opposite of that of the wild type: PREG binding resulted in a 92\% shift to the high-spin state, while PROG binding saw a complete transition (panels A and B of Figure 3, respectively). In the case of lyase substrates, the wild-type enzyme again exhibited a more complete spin shift for substrates presenting a C-3 alcohol. For OHPREG and OHPROG, conversion to the high-spin state was $86 \%$ and $79 \%$, respectively. Again, for the N202S mutant, the effects of substrates were reversed versus those of the wild type: OHPREG induced an $83 \%$ shift to the high-spin state, while OHPROG now caused an $88 \%$ conversion (panels $C$ and $D$ of Figure 3 , respectively). Expulsion of water as a ligand to the heme iron is highly sensitive to the presence and orientation of the substrate in the distal active site pocket. Therefore, these results offer evidence that subtle differences in interactions between A-ring substituents and the residue at position 202 are reliably translated as differences in positioning of the D-ring near the heme.

Next, we determined the role of N202 mutations in the function of CYP17A1. Steady state turnover rates for both wild-type and mutant enzymes were measured in parallel using saturating concentrations of OHPREG or OHPROG in the presence of a 4 -fold molar excess of cytochrome $b_{5}$ and cytochrome P450 oxidoreductase relative to CYP17A1. Interestingly, we found that substitution of N202 with a serine residue not only reversed binding affinity and spin state conversion but also had a significant impact on the product formation rates for the lyase reaction (Figure 4). As expected, formation of DHEA by the N202S mutant was impaired (0.12 $\mathrm{min}^{-1}$ ) relative to that by the wild type $\left(0.41 \mathrm{~min}^{-1}\right)$. However, the product formation rate of $A D$ more than doubled for the mutant protein relative to that for the wild type, increasing from 0.20 to $0.49 \mathrm{~min}^{-1}$. These differences in the rate of enzyme turnover are unrelated to the changes in binding affinity, as all experiments were performed in the presence of saturating substrate concentrations. Rather, differences in product formation rates in the mutant protein are likely reflective of the substrate adopting an orientation more favorable for catalysis in the case of OHPROG, or less favorable in the case of OHPREG as revealed by rR spectroscopy.

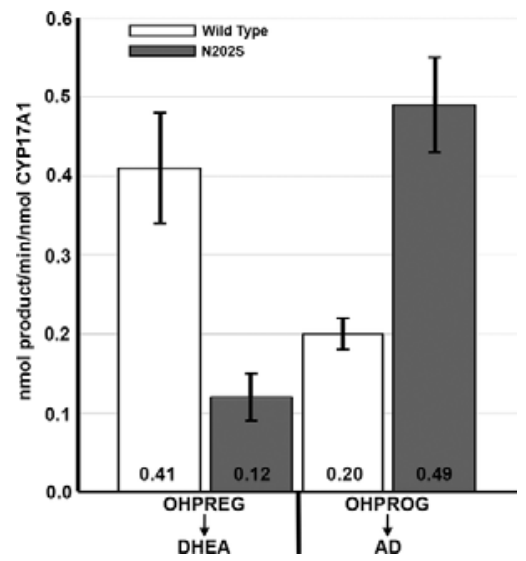

Figure 4. Steady state turnover of WT and N202S CYP17A1. Error bars represent \pm 1 standard deviation.

\section{Resonance Raman Spectroscopy of the Oxy-Ferrous Form of N202S CYP17A1}

In a previous study, we successfully documented a unique pattern of hydrogen bonding in which the 17-OH of the substrate forms a direct $\mathrm{H}$-bond to the distal oxygen of the oxy-ferrous complex when OHPROG is a substrate, and the proximal oxygen atom when OHPREG is a substrate.(9) This hydrogen bonding pattern was found to persist in the subsequent peroxo-ferric species,(10)leaving the distal oxygen free to initiate a nucleophilic attack on the substrate C-20 carbonyl when OHPREG was a substrate. To explore the subtle changes in substrate orientation caused by the $\mathrm{N} 202 \mathrm{~S}$ mutation, we used $\mathrm{rR}$ spectroscopy to examine the nature of $\mathrm{H}$ bonding interactions between the substrate 17-OH and iron-bound dioxygen. The rR spectra of ND:CYP17A1 N202S samples containing PROG and PREG substrates are identical and exhibit clear v(Fe-O) and v(O-O) stretching modes at 535 and $1139 \mathrm{~cm}^{-1}$, respectively (Figure 5 , traces $\mathrm{A}$ and $\mathrm{B}$ ). The ${ }^{16} \mathrm{O}_{2}-{ }^{18} \mathrm{O}_{2}$ isotopic shifts are 
as expected,(26-28) i.e., 29 and $66 \mathrm{~cm}^{-1}$ for $\mathrm{v}(\mathrm{Fe}-\mathrm{O})$ and $\mathrm{v}(\mathrm{O}-\mathrm{O})$ modes, respectively. It is noted that the spectral patterns of the PROG- and PREG-bound mutant are almost identical to those of wild-type samples with corresponding substrates; i.e., the differences in frequencies are $<1 \mathrm{~cm}^{-1}$ (Table 2). Differences in the orientation of these two substrates within the mutant active site do not substantially impact the $\mathrm{Fe}-\mathrm{O}-\mathrm{O}$ fragment because of the lack of a substrate-associated polar $\mathrm{OH}$ group within the immediate vicinity of the $\mathrm{Fe}-\mathrm{O}-\mathrm{O}$ fragment.

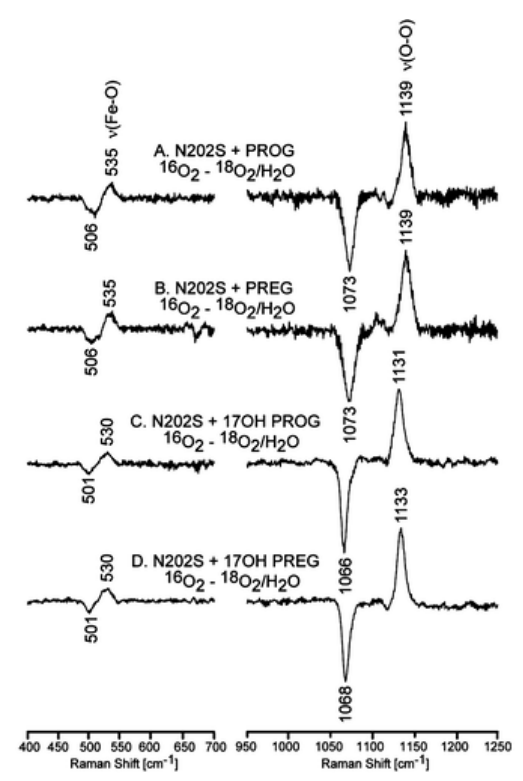

Figure 5. ${ }^{16} \mathrm{O}_{2}-{ }^{18} \mathrm{O}_{2}$ difference traces of the (A) PROG-, (B) PREG-, (C) OHPROG-, and (D) OHPREG-bound N202S mutant in the low-frequency (left) and high-frequency (right) regions.

Table 2. Comparison of the v(Fe-O) and v(0-0) Modes for Wild-Type and N202S CYP17A1

\begin{tabular}{|l|l|l|l|}
\hline & $\mathrm{v}(\mathrm{Fe}-\mathrm{O})\left(\mathrm{cm}^{-1}\right)$ & $v(\mathrm{O}-\mathrm{O})\left(\mathrm{cm}^{-1}\right)$ & ref \\
\hline PREG (WT) & 535 & 1140 & 9 \\
\hline OHPREG (WT) & 526 & 1135 & 9 \\
\hline Swavenumber & -9 & -5 & 9 \\
\hline PROG (WT) & 536 & 1140 & 9 \\
\hline OHPROG (WT) & 542 & 1131 & 9 \\
\hline Swavenumber & +6 & -9 & 9 \\
\hline PREG (N202S) & 535 & 1139 & - \\
\hline OHPREG (N202S) & 530 & 1133 & - \\
\hline Dwavenumber & -5 & -6 & - \\
\hline PROG (N202S) & 535 & 1139 & - \\
\hline OHPROG (N202S) & 530 & 1131 & - \\
\hline Swavenumber & -5 & -8 & - \\
\hline
\end{tabular}

As shown in Figure 5 , high-quality rR spectra were also obtained for the dioxygen adducts of the samples bearing the hydroxylated substrates, OHPROG and OHPREG. The OHPROG sample exhibits $v(\mathrm{O}-\mathrm{O})$ and $v(\mathrm{Fe}-\mathrm{O})$ modes at 1131 and $530 \mathrm{~cm}^{-1}$, respectively, with expected ${ }^{16} \mathrm{O}_{2}-{ }^{18} \mathrm{O}_{2}$ isotopic shifts (65 and $29 \mathrm{~cm}^{-1}$, respectively). A similar spectral pattern is observed for the OHPREG-bound sample; the $\mathrm{v}(\mathrm{O}-\mathrm{O})$ stretching mode is observed at 1133 $\mathrm{cm}^{-1}\left(65 \mathrm{~cm}^{-1}\right.$ downshift upon ${ }^{18} \mathrm{O}_{2}$ substitution), and the $v(\mathrm{Fe}-\mathrm{O})$ mode is observed at $530 \mathrm{~cm}^{-1}$, where the ${ }^{16} \mathrm{O}_{2}-{ }^{18} \mathrm{O}_{2}$ difference is $29 \mathrm{~cm}^{-1}$. 
Referring to Figure 5 and Table 2, which reports $\mathrm{rR}$ spectral data for the $\mathrm{O}_{2}$ adducts of the wild type and N202S mutant, we emphasize that no significant changes in the internal modes of the Fe-O-O fragment were seen for the nonpolar PROG and PREG substrates; e.g., the $v(\mathrm{Fe}-\mathrm{O})$ modes are seen at $\sim 535 \mathrm{~cm}^{-1}$, and the $v(\mathrm{O}-\mathrm{O})$ modes are observed at $\sim 1140 \mathrm{~cm}^{-1}$ for the WT and N202 mutant containing PROG and PREG substrates. On the other hand, the spectra acquired for the N202S samples containing OHPROG and OHPREG are significantly different from the data acquired for the WT protein, with the changes mostly localized on the v(Fe-O) vibrations. Thus, all four samples containing hydroxylated substrates, including WT and N202S mutant proteins, exhibit a v(O-O) mode shifted by $5-9 \mathrm{~cm}^{-1}$ [ $\Delta$ wavenumber (Table 2)] from its position for the nonhydroxylated substrates, behavior that is consistent with the introduction of a new $\mathrm{H}$-bonding residue in the vicinity of the Fe-O-O fragment.

Most importantly, the variations of the $\mathrm{v}(\mathrm{Fe}-\mathrm{O})$ modes in response to the two different hydroxylated substrates, OHPROG and OHPREG, are revealing. In a previous work $(9)$ that focused on the WT protein, convincing arguments, supported by experimental(29-35) and computational(36) studies, were made to suggest that the C$\mathrm{OH}$ group of OHPROG interacts with the terminal oxygen $\left(\mathrm{O}_{t}\right)$ of the Fe- $\mathrm{O}_{\mathrm{p}}-\mathrm{O}_{\mathrm{t}}$ fragment, causing a significant shift of the $v(\mathrm{Fe}-\mathrm{O})$ mode to a higher frequency $\left(542 \mathrm{~cm}^{-1}\right)$, relative to the values observed for the nonpolar substrates. Conversely, the $\mathrm{C}-\mathrm{OH}$ group of OHPREG interacts with the proximal $\left(\mathrm{O}_{p}\right)$ oxygen atom of the $\mathrm{Fe}-\mathrm{O}_{p}-$ $\mathrm{O}_{\mathrm{t}}$ fragment, causing a shift of the $\mathrm{v}(\mathrm{Fe}-\mathrm{O})$ to a substantially lower frequency $\left(526 \mathrm{~cm}^{-1}\right)$.

Important for this work is the fact that the apparent substrate repositioning caused by the N202S mutation drastically alters the resultant interactions of the substrate-associated $\mathrm{OH}$ groups with the $\mathrm{O}_{\mathrm{p}}$ and $\mathrm{O}_{\mathrm{t}}$ atoms of the $\mathrm{Fe}-\mathrm{O}_{\mathrm{p}}-\mathrm{O}_{\mathrm{t}}$ fragment, as is evident from the observed shifts of the $\mathrm{v}(\mathrm{Fe}-\mathrm{O})$ modes. The $v(\mathrm{Fe}-\mathrm{O})$ mode in the mutant sample containing OHPROG is observed at a frequency $12 \mathrm{~cm}^{-1}$ lower than that of the $v(\mathrm{Fe}-\mathrm{O})$ mode in the OHPROG-bound WT sample $\left(530 \mathrm{~cm}^{-1}\right.$ in N202S vs $542 \mathrm{~cm}^{-1}$ in the WT). Conversely, the v(Fe-O) mode of the OHPREG sample is $4 \mathrm{~cm}^{-1}$ higher in the mutant than it is in the WT sample $\left(530 \mathrm{~cm}^{-1}\right.$ in N202S vs $526 \mathrm{~cm}^{-1}$ in the WT) (Table 2 and Figure 6).

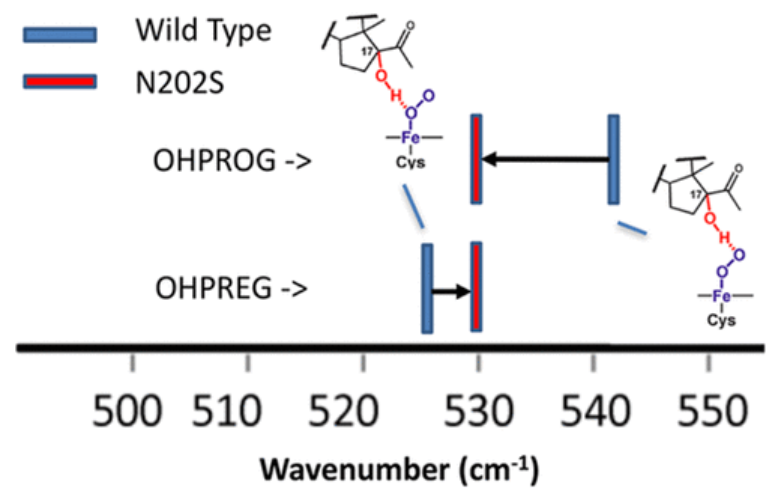

Figure 6. Alteration of the pattern of bonding of hydrogen of wild-type and N202S CYP17A1 to the heme-bound dioxygen. The Fe-O wavenumber is indicated on the abscissa.

While it is possible that the alteration of $\mathrm{v}(\mathrm{Fe}-\mathrm{O})$ stretching frequencies in the $\mathrm{P} 450$ samples with hydroxylated substrates might arise from electrostatic or structural changes on the proximal side of the heme pocket, such changes are usually reflected in changes in Fe-S bond strength. For instance, it was shown previously(37) that the alteration of polar interaction among anionic reductase, putidaredoxin, and the positively charged proximal side of the CYP101 led to a $3 \mathrm{~cm}^{-1}$ upshift of the $v(\mathrm{Fe}-\mathrm{S})$ mode. Enhanced electron donation through a $\pi$-bonding interaction between a sulfur $\mathrm{p}$ orbital and the Fe $d \pi$ orbital resulted in significant strengthening of the $\mathrm{Fe}-\mathrm{S}$ bond. However, measurements of N202S samples containing ferric OHPROG or OHPREG substrate using UV excitation revealed that the $v(\mathrm{Fe}-\mathrm{S})$ stretching mode is observed at $347 \mathrm{~cm}^{-1}$ in the spectra of both samples (data not shown). This observation is consistent with the lack of a substrate effect on Fe-S bond strength in the 
WT protein, where the $v(\mathrm{Fe}-\mathrm{S})$ stretching mode was also observed at $347 \mathrm{~cm}^{-1}$ in the presence of each of the four substrates.(38) This lack of changes in the $v(\mathrm{Fe}-\mathrm{S})$ mode among all studied samples effectively argues that the proximal factors are negligible and that the observed changes in $\mathrm{v}(\mathrm{Fe}-\mathrm{O})$ modes arise only from the distal side effects, i.e., hydrogen bonding interactions with the Fe-O-O fragment.

One reasonable interpretation of these shifts is that the downshift of the $v(\mathrm{Fe}-\mathrm{O})$ mode in the mutant sample with OHPROG reflects a shift in the $\mathrm{H}$-bonding interaction of the $\mathrm{C}-\mathrm{OH}$ group from the $\mathrm{O}_{\mathrm{t}}$ atom to the $\mathrm{O}_{p}$ atom of the Fe-O-O fragment, though not to such a degree as was seen for the WT case with the OHPREG substrate.(9) Such a change in directionality of the $\mathrm{H}$-bonding interaction is a clear indication that the positions of the OHPREG and OHPROG lyase substrates are mediated, at least in part, by interactions between the substrate C-3 substituent and the residue at position 202 in human CYP17A1.

The discrete positioning of the substrate in the active site of a cytochrome P450 can have a profound impact on the catalytic efficiency of the enzyme. Because of the complexity of the P450 reaction cycle, there can be alterations in multiple steps. Interaction of the substrate with the distal water in the ferric low-spin complex can result in a significant modulation of the spin-state equilibrium with a corresponding impact on the ferric-ferrous redox potential and electron transfer rates. Structural changes that allow more or less water into the enzyme active site, with a resultant change in active site polarity, can also modulate the degree of coupling of pyridine nucleotide reducing equivalents to the product. Overall positioning relative to the heme-bound "active oxygen", either a Compound I or peroxoanion, is of obvious importance to product formation. In all likelihood, multiple structural and dynamic factors may be involved.

It is interesting, however, to link the observed changes in hydrogen bonding between the 17-OH groups of these steroids with results suggesting the involvement of the peroxoanion intermediate in the initiation of the carboncarbon bond scission event. In previous work,(13) we utilized kinetic solvent isotope effects (KSIEs) to document the nature of a peroxoanion intermediate as a critical branching point in lyase catalysis. Observation of an unusual inverse KSIE suggested a reactivity of the peroxoanion before protonation leading to $\mathrm{O}-\mathrm{O}$ bond scission and formation of the Compound I metal-oxo intermediate that is active in normal hydroxylation chemistry. Rather, nucleophilic attack of the distal oxygen of the peroxo anion on the C-20 carbonyl would yield a hemiketal intermediate that was trapped at low temperatures.(10) Previous publications also used resonance Raman spectroscopy to monitor the differential hydrogen bonding patterns between the 17-OH group of OHPREG and OHPROG and the proximal and distal oxygen atoms in the ferrous dioxygen intermediate and showed that these patterns persist as the peroxoanion is formed. $(9,10)$ The results presented here document how substrate repositioning due to interactions at the A-ring can modulate the bonding of hydrogen to the heme-bound oxy-ferrous complex and thus contribute to a mechanistic understanding.

If the mechanism of lyase activity involves the peroxoanion as we and others have suggested, $(10,11,13)$ then the observed increase in the level of bonding of hydrogen to $O_{p}$ would be expected to free the terminal oxygen $\mathrm{O}_{\mathrm{t}}$ to initiate a nucleophilic attack on the $\mathrm{C}-20$ carbonyl, thus potentially increasing the lyase activity of the N202S mutant of OHPROG as compared to that of the wild type.

Such an interpretation is supported by the product formation data reported herein, which show a 2-fold higher level of production of AD from OHPROG by the N202S mutant than by the wild type. On the other hand, the upshift of the $v(\mathrm{Fe}-\mathrm{O})$ mode in the mutant sample containing OHPREG reflects a weakening of the bonding of hydrogen to $O_{p}$, relative to that of the WT protein (Figure 6). This interpretation is also supported by the product formation studies, which show that the level of production of DHEA from OHPREG in the mutant is approximately $25 \%$ of that observed for the WT sample. 
From another perspective, it is noted that the $\mathrm{rR}$ spectral patterns of dioxygen adducts of the mutant in the presence of both hydroxylated substrates are consistent with virtually identical H-bonding interactions with the $\mathrm{Fe}-\mathrm{O}_{\mathrm{p}}-\mathrm{O}_{\mathrm{t}}$ fragment, both being mildly poised for peroxo attack on $\mathrm{C}-20,(9,10)$ yet the product formation rate of the OHPROG sample $\left(0.49 \mathrm{~min}^{-1}\right)$ is 4 times higher than that of the OHPREG-bound sample $\left(0.12 \mathrm{~min}^{-1}\right)$. This observation leads to the conclusion that, while $\mathrm{H}$-bonding interactions can play a significant role in controlling activity, when they are apparently equivalent, other factors certainly influence the overall enzymatic activity.

In addition to other confounding complexities in the $\mathrm{P} 450$ reaction cycle mentioned previously, we also note that the discrepancy between the magnitude of the change in $\mathrm{v}(\mathrm{Fe}-\mathrm{O})$ modes and product formation rates in WT versus $\mathrm{N} 202 \mathrm{~S}$ may also be attributable to the absence of reductase and cytochrome $b_{5}$ in our rR samples. As noted, the $\mathrm{Fe}-\mathrm{O}-\mathrm{O}$ fragment is especially susceptible to the strength and orientation of distal pocket $\mathrm{H}$-bonding interactions.(36) There is ample precedent to suggest that binding of the redox partner to an oxy adduct of a cytochrome P450 (CYP101 and CYP11A1) can alter H-bonding interactions with the Fe-O-O fragments.(39, 40) These considerations suggest that further, more elaborate, and technically demanding rR spectroscopic studies are required to fully clarify the nature of $\mathrm{H}$-bonding interactions with the $\mathrm{Fe}-\mathrm{O}-\mathrm{O}$ fragments of these enzymes in the presence of redox partners.

In conclusion, these spectroscopic and functional studies provide convincing evidence that the N202 residue of CYP17A1 plays a critical role in defining not only the affinity for either OHPREG or OHPROG but also the orientation of these hydroxylated substrates in the active site. These results demonstrate that minute changes resulting from a single-point mutation in the hydrogen bonding environment in the active site cavity, even when distant from the heme catalytic center, are capable of modulating this enzyme's lyase activity. Notably, these results highlight the ability of this single residue to fine-tune the activity of CYP17A1 to adjust to the unique steroidogenic needs of various species.

\section{Author Contributions}

Y.K. and M.C.G. prepared the protein and samples. M.C.G. and P.J.M. performed the experiments. M.C.G., P.J.M., J.R.K., and S.G.S. analyzed data and prepared the manuscript.

\section{Funding Information}

This work was supported by National Institutes of Health Grants GM118145 to S.G.S. and GM110428 to J.R.K. and S.G.S.

The authors declare no competing financial interest.

\section{Acknowledgment}

The authors acknowledge frequent discussions with Dr. Ilia Denisov, whose input was exceptionally valuable in data analysis.

Abbreviations
\begin{tabular}{|l|l|}
\hline OHPREG & $17 \alpha$-hydroxypregnenolone \\
\hline OHPROG & $\mathbf{1 7} \alpha$-hydroxyprogesterone \\
\hline AD & androstenedione \\
\hline CYP17A1 & cytochrome P450 CYP17A1 \\
\hline DHEA & dehydroepiandrosterone \\
\hline HS & high-spin \\
\hline PREG & pregnenolone \\
\hline
\end{tabular}




\begin{tabular}{|l|l|}
\hline LS & low-spin \\
\hline PROG & progesterone \\
\hline RR & resonance Raman \\
\hline WT & wild type. \\
\hline
\end{tabular}

\section{References}

1 Nakajin, S. and Hall, P. F. (1981) Microsomal cytochrome P-450 from neonatal pig testis. Purification and properties of $A_{21}$ steroid side-chain cleavage system ( $17 \alpha$-hydroxylase- $C_{17,20}$ lyase J. Biol. Chem. 256, 3871-3876

$\underline{2}$ Nakajin, S., Shively, J. E., Yuan, P. M., and Hall, P. F. (1981) Microsomal Cytochrome P-450 from Neonatal Pig Testis: Two Enzymatic Activities (17 $\alpha$-hydroxylase and $C_{17,20}$-lyase) Associated with One Protein Biochemistry 20, 4037- 4042DOI: 10.1021/bi00517a014

$\underline{3}$ DeVore, N. M. and Scott, E. E. (2012) Structures of cytochrome P450 17A1 with prostate cancer drugs abiraterone and TOK-001 Nature 482, 116-119DOI: 10.1038/nature10743

4 Auchus, R. J., Lee, T. C., and Miller, W. L. (1998) Cytochrome $b_{5}$ Augments the 17,20-Lyase Activity of Human P450c17 without Direct Electron Transfer J. Biol. Chem. 273, 3158-3165DOI: 10.1074/jbc.273.6.3158

$\underline{5}$ Khatri, Y., Gregory, M. C., Grinkova, Y. V., Denisov, I. G., and Sligar, S. G. (2014) Active site proton delivery and the lyase activity of human CYP17A1 Biochem. Biophys. Res. Commun. 443,179-184DOI: 10.1016/j.bbrc.2013.11.094

$\underline{6}$ Gilep, A. A., Sushko, T. A., and Usanov, S. A. (2011) At the crossroads of steroid hormone biosynthesis: The role, substrate specificity and evolutionary development of CYP17 Biochim. Biophys. Acta, Proteins Proteomics 1814, 200- 209DOI: 10.1016/j.bbapap.2010.06.021

$\underline{7}$ Gilep, A., Estabrook, R., and Usanov, S. (2003) Molecular Cloning and Heterologous Expression in E. coli of Cytochrome P45017A. Comparison of Structural and Functional Properties of Substrate-Specific Cytochromes P450 from Different Species Biochemistry 68, 86-98DOI: 10.1023/A:1022101703670

$\underline{8}$ Petrunak, E. M., DeVore, N. M., Porubsky, P. R., and Scott, E. E. (2014) Structures of human steroidogenic cytochrome P450 17A1 with substrates J. Biol. Chem. 289, 32952-32964DOI: 10.1074/jbc.M114.610998

$\underline{9}$ Gregory, M., Mak, P. J., Sligar, S. G., and Kincaid, J. R. (2013) Differential Hydrogen Bonding in Human CYP17 Dictates Hydroxylation versus Lyase Chemistry. Angew Angew. Chem., Int. Ed. 52,5342-5345DOI: 10.1002/anie.201300760

10 Mak, P. J., Gregory, M. C., Denisov, I. G., Sligar, S. G., and Kincaid, J. R. (2015) Unveiling the crucial intermediates in androgen production Proc. Natl. Acad. Sci. U. S. A. 112, 15856-15861DOI: 10.1073/pnas.1519376113

11 Akhtar, M., Wright, J. N., and Lee-Robichaud, P. (2011) A review of mechanistic studies on aromatase (CYP19) and 17 $\alpha$-hydroxylase-17,20-lyase (CYP17) J. Steroid Biochem. Mol. Biol. 125,2-12DOI: 10.1016/j.jsbmb.2010.11.003

12 Bonomo, S., Jørgensen, F. S., and Olsen, L. (2017) Mechanism of Cytochrome P450 17A1-Catalyzed Hydroxylase and Lyase Reactions J. Chem. Inf. Model. 57, 1123-1133DOI: 10.1021/acs.jcim.6b00759

13 Gregory, M. C., Denisov, I. G., Grinkova, Y. V., Khatri, Y., and Sligar, S. G. (2013) Kinetic Solvent Isotope Effect in Human P450 CYP17A1-Mediated Androgen Formation: Evidence for a Reactive Peroxoanion Intermediate J. Am. Chem. Soc. 135, 16245-16247DOI: 10.1021/ja4086403

14 Bayburt, T. H. and Sligar, S. G. (2010) Membrane protein assembly into Nanodiscs FEBS Lett. 584, 1721-1727DOI: 10.1016/j.febslet.2009.10.024 
15 Ritchie, T. K., Grinkova, Y. V., Bayburt, T. H., Denisov, I. G., Zolnerciks, J. K., Atkins, W. M., andSligar, S.

G. (2009) Reconstitution of Membrane Proteins in Phospholipid Bilayer NanodiscsMethods Enzymol. 464, 211- 231DOI: 10.1016/S0076-6879(09)64011-8

16 Alami, M., Dalal, K., Lelj-Garolla, B., Sligar, S. G., and Duong, F. (2007) Nanodiscs unravel the interaction between the SecYEG channel and its cytosolic partner SecA EMBO J. 26, 1995-2004DOI: 10.1038/sj.emboj.7601661

17 Denisov, I. G., Grinkova, Y. V., Lazarides, A. A., and Sligar, S. G. (2004) Directed Self-Assembly of Monodisperse Phospholipid Bilayer Nanodiscs with Controlled Size J. Am. Chem. Soc. 126(11) 3477- 3487DOI: 10.1021/ja0393574

18 Denisov, I. G. and Sligar, S. G. (2017) Nanodiscs in Membrane Biochemistry and BiophysicsChem. Rev. 117, 4669-4713DOI: 10.1021/acs.chemrev.6b00690

19 Luthra, A., Gregory, M., Grinkova, Y. V., Denisov, I. G., and Sligar, S. G. (2013) Nanodiscs in the studies of membrane-bound cytochrome P450 enzymes Methods Mol. Biol. 987, 115- 127DOI: 10.1007/978-162703-321-3_10

20 Segel, I. (1975) Enzyme Kinetics: Behavior and Analysis of Rapid Equilibrium and Steady-State Enzyme Systems, p 957, Wiley, New York.

$\underline{21}$ Luthra, A., Denisov, I. G., and Sligar, S. G. (2011) Spectroscopic features of cytochrome P450 reaction intermediates Arch. Biochem. Biophys. 507, 26- 35DOI: 10.1016/j.abb.2010.12.008

22 Mulrooney, S. B. and Waskell, L. (2000) High-level expression in Escherichia coli and purification of the membrane-bound form of cytochrome b(5) Protein Expression Purif. 19, 173-178DOI: 10.1006/prep.2000.1228

$\underline{23}$ Shen, A. L., Porter, T. D., Wilson, T. E., and Kasper, C. B. (1989) Structural analysis of the FMN binding domain of NADPH-cytochrome P-450 oxidoreductase by site-directed mutagenesis J. Biol. Chem. 264, 7584- 7589

$\underline{24}$ Grinkova, Y. V., Denisov, I. G., and Sligar, S. G. (2010) Functional reconstitution of monomeric CYP3A4 with multiple cytochrome P450 reductase molecules in Nanodiscs Biochem. Biophys. Res.

Commun. 398, 194- 198DOI: 10.1016/j.bbrc.2010.06.058

$\underline{25}$ Duggal, R., Liu, Y., Gregory, M. C., Denisov, I. G. I. G., Kincaid, J. R. J. R., and Sligar, S. G. S. G.(2016) Evidence that cytochrome b5 acts as a redox donor in CYP17A1 mediated androgen synthesis Biochem. Biophys. Res. Commun. 477, 202- 208DOI: 10.1016/j.bbrc.2016.06.043

26 Bangcharoenpaurpong, O., Rizos, A. K., Champion, P. M., Jollie, D., and Sligar, S. G. (1986)Resonance Raman detection of bound dioxygen in cytochrome P-450cam J. Biol. Chem. 261,8089-8092

$27 \mathrm{Hu}$, S., Schneider, A. J., and Kincaid, J. R. (1991) Resonance raman studies of oxycytochrome P450cam: effect of substrate structure on v(O-O) and v(Fe-O $\left.\mathrm{O}_{2}\right) \mathrm{J}$. Am. Chem. Soc. 113, 4815-4822DOI: 10.1021/ja00013a016

28 Mak, P. J. (2016) Resonance Raman spectroscopy as a structural probe of cytochrome P450 enzymatic cycle. In Handbook of Porphyrin Science (Kadish, K. M., Smith, K., and Guilard, R., Eds.) 42nd ed., pp 1-120, World Scientific Publishing Co., Singapore.

29 Das, T. K., Couture, M., Ouellet, Y., Guertin, M., and Rousseau, D. L. (2001) Simultaneous observation of the $\mathrm{O}-\mathrm{O}$ and $\mathrm{Fe}-\mathrm{O}_{2}$ stretching modes in oxyhemoglobins Proc. Natl. Acad. Sci. U. S. A. 98, 479-484DOI: 10.1073/pnas.98.2.479

30 Lu, C., Egawa, T., Wainwright, L. M., Poole, R. K., and Yeh, S.-R. R. (2007) Structural and Functional Properties of a Truncated Hemoglobin from a Food-borne Pathogen Campylobacter jejuni J. Biol. Chem. 282, 13627- 13636DOI: 10.1074/jbc.M609397200

31 Yeh, S., Couture, M., Ouellet, Y., Guertin, M., and Rousseau, D. L. (2000) A Cooperative Oxygen Binding Hemoglobin from Mycobacterium tuberculosis J. Biol. Chem. 275, 1679-1684DOI:

10.1074/jbc.275.3.1679 
32 Yoshimura, H., Yoshioka, S., Kobayashi, K., Ohta, T., Uchida, T., Kubo, M., Kitagawa, T., andAono, S. (2006) Specific Hydrogen-Bonding Networks Responsible for Selective $\mathrm{O}_{2}$ Sensing of the Oxygen Sensor Protein HemAT from Bacillus subtilis Biochemistry 45, 8301- 8307DOI: 10.1021/bi060315c

33 Li, D., Kabir, M., Stuehr, D. J., Rousseau, D. L., and Yeh, S.-R. (2007) Substrate- and Isoform-Specific Dioxygen Complexes of Nitric Oxide Synthase J. Am. Chem. Soc. 129, 6943-6951DOI: 10.1021/ja070683j

34 Rousseau, D. L., Li, D., Couture, M., and Yeh, S.-R. (2005) Ligand-protein interactions in nitric oxide synthase J. Inorg. Biochem. 99, 306-323DOI: 10.1016/j.jinorgbio.2004.11.007

35 Couture, M., Stuehr, D. J., and Rousseau, D. L. (2000) The ferrous dioxygen complex of the oxygenase domain of neuronal nitric- oxide synthase J. Biol. Chem. 275, 3201-3205DOI: 10.1074/jbc.275.5.3201

36 Spiro, T. G., Soldatova, A. V., and Balakrishnan, G. (2013) CO, NO and $\mathrm{O}_{2}$ as vibrational probes of heme protein interactions Coord. Chem. Rev. 257, 511- 527DOI: 10.1016/j.ccr.2012.05.008

37 Unno, M., Christian, J. F., Benson, D. E., Gerber, N. C., Sligar, S. G., and Champion, P. M. (1997)Resonance Raman investigations of cytochrome P450(cam) complexed with putidaredoxin J. Am. Chem. Soc. 119, 6614- 6620DOI: 10.1021/ja963785a

38 Mak, P. J., Gregory, M. C., Sligar, S. G., and Kincaid, J. R. (2014) Resonance Raman Spectroscopy Reveals That Substrate Structure Selectively Impacts the Heme-Bound Diatomic Ligands of CYP17 Biochemistry 53, 90- 100DOI: 10.1021/bi4014424

39 Sjodin, T., Christian, J. F., Macdonald, I. D. G., Davydov, R., Unno, M., Sligar, S. G., Hoffman, B. M., and Champion, P. M. (2001) Resonance Raman and EPR Investigations of the D251N Oxycytochrome P450cam/Putidaredoxin Complex Biochemistry 40, 6852-6859DOI: 10.1021/bi002510b

$\underline{40}$ Zhu, Q., Mak, P. J., Tuckey, R. C., and Kincaid, J. R. (2017) Active Site Structures of CYP11A1 in the Presence of Its Physiological Substrates and Alterations upon Binding of AdrenodoxinBiochemistry 56, 5786- 5797DOI: 10.1021/acs.biochem.7b00766 